\title{
Epidemiology of Angle-closure Glaucoma
}

\section{David S Friedman}

Johns Hopkins University, Baltimore, MD, USA

e-mail: david.friedman@jhu.edu

\section{OVERVIEW}

Even though primary angle-closure glaucoma (PACG) appears to be less prevalent than open-angle glaucoma, PACG may blind a higher proportion of individuals with the disease, ${ }^{1-3}$ and therefore may be responsible for as much blindness worldwide as open-angle glaucoma. ${ }^{4}$ PACG occurs in about 0.5 percent of whites and blacks over the age of 40 , and about 1.5 percent of Chinese and Indian individuals in this age group. ${ }^{3,5-8}$ Foster and colleagues reported in one population-based study that half of all individuals diagnosed with PACG were blind in at least one eye. ${ }^{1}$ Even though PACG accounts for 35 percent of all glaucoma cases in China, 90 percent of those blind from glaucoma (5.2 million total) have PACG. ${ }^{9}$ Similar findings were reported for Asian Indians where 41 percent of those with PACG were blind in one or both eyes from this condition. ${ }^{3}$ Unpublished data from the Baltimore Eye Survey indicate that 0.4 percent of whites and 0.6 percent of blacks over the age of 40 have PACG (James Tielsch, personal communication, 2006) which is in keeping with rates found in a population-based study of PACG in Africa. ${ }^{7}$

The world is aging, particularly Asia. Between 2005 and 2025, the 50 and over population of China will increase from 282 million persons to 515 million and that of India will increase from 162 to 326 million. Such a dramatic increase in the numbers of persons with the highest rates of PACG will lead to a massive increase in the total number presenting for care. Better screening and prophylactic strategies will be needed to deal with the inexorable force of aging in this region.

\section{TERMINOLOGY}

Primary angle-closure glaucoma (PACG) is reserved for persons who have no secondary causes of angle-closure (e.g. uveitis or angle neovascularization) who also have "closed" angles and optic nerve damage characteristic of glaucoma. The terminology used to describe angle-closure is confusing because definitions used over the last 50 years have been inconsistent. A recent consensus group involving over 100 glaucoma specialists from around the world reviewed the most common terminology applied to PACG and proposed guidelines for defining various conditions related to PACG. ${ }^{10}$ This work built on a seminal article that outlined a proposed terminology for PACG nearly a decade ago. ${ }^{11}$ First, as stated above, this nomenclature recognizes that glaucoma is present only when there is characteristic glaucomatous optic neuropathy with an associated loss of peripheral vision as demonstrated by visual field testing. Both structural and functional damage are present. In the past, it was common to categorize patients as having PACG even though the optic nerves were healthy and there was no evidence of functional loss. Researchers and clinicians have defined the disease by the presence of signs (an elevated intraocular pressure [IOP] or the presence of peripheral anterior synechiae [PAS]) or by whether or not the eye pressure increased when the patient is subjected to a provocative test.

The term "primary angle-closure suspect (PACS)," and not persons with "occludable angles," is now the agreed upon standard for describing persons who have appositional closure of the anterior chamber angle on gonioscopy. The term "occludable angles" has typically been used when an observer using standard (non-compression) gonioscopy cannot see the pigmented trabecular meshwork for 270 degrees or more of the angle. This term is arbitrary because it is not known what proportion of these individuals will ever occlude, and it is not clear that 270 degrees is more appropriate than 180 degrees, or even 90 degrees. In fact, we know that the vast majority of these angles will never occlude based on the much greater prevalence of narrow angles than PACG. ${ }^{9}$ The consensus panel recommended that 180 degrees or more of appositional closure (defined by peripheral iris in contact with the posterior, usually pigmented, trabecular meshwork) in the absence of other pathology may be considered as a new standard for defining PACS. The American Academy of Ophthalmology Preferred Practice Patterns publication also refers to these individuals as primary angle-closure suspects. ${ }^{6}$ This practice guideline confirms the uncertainty regarding such patients: "There is no evidence that iridotomy is indicated merely for the presence of narrow but open-angles, but such patients should be followed carefully for IOP elevation, evidence of progressive narrowing, or development of synechial angle-closure."

Individuals with appositional closure as defined above may develop signs that this condition is indeed leading to ocular damage. Some individuals with appositional closure on 
gonioscopy have a statistically elevated IOP (typically defined as an IOP greater than two standard deviations above the norm for the population), or evidence of damage to the angle structures (i.e. PAS). These individuals do not have glaucoma (i.e. they do not have optic nerve and/or visual field damage), but they have evidence that the gonioscopic angle findings are associated with changes in the eye that may lead to glaucoma over time. Such individuals are said to have primary angleclosure (PAC). Finally, some individuals with narrow angles have glaucomatous optic nerve damage with associated loss of visual field. These individuals have primary angle-closure glaucoma (PACG).

One final category that is somewhat different from those discussed above is "acute angle-closure" (AAC). The AAC is characterized by sudden, typically painful increases in intraocular pressure with associated symptoms and signs. Individuals undergoing AAC are often nauseated, see halos around light, and notice decreased vision in the affected eye. Clinical examination findings include corneal edema, ciliary injection, anterior chamber reaction, and a closed-angle on gonioscopy. AAC can cause severe vision loss in a significant number of those suffering an attack. ${ }^{12-14}$ The damage to the optic nerve can be consistent with other forms of glaucoma, or can be atypical, revealing mostly pallor without substantial excavation. This occurs 20 percent of the time in one recent publication..$^{12}$ Due to this potential form of optic nerve damage, the most recent consensus definition of PACG includes the presence of a pale, non-excavated nerve associated with loss of visual field. ${ }^{10}$ However, recent research indicates that 80 percent of PACG occurs without an episode of AAC., ${ }^{2,5}$

\section{RISK FACTORS AND SCREENING}

Much of the early literature on risk factors for angle-closure was published by two researchers, Lowe and Alsbirk. ${ }^{15-18}$ They identified an association with relatively anterior lens position and a proportionally thicker lens with the presence of PACG. Both of these conditions are associated with a shallow anterior chamber depth, one of the strongest risk factors for PACG. ${ }^{19}$ Affected eyes are frequently hypermetropic with a short axial length, and have small corneal diameters and radii of curvature. Interestingly, even though PACG is more prevalent in China, one study found that Chinese, blacks and whites had similar mean anterior chamber depths, indicating that other factors may contribute to higher rates among Chinese. ${ }^{20}$ While all the ocular biometric parameters described are clearly associated with the presence of PACG and acute closure attacks, none of them has been demonstrated to be associated with a poor outcome for individuals who are PAC suspects and are not treated with prophylactic iridotomy. Other important risk factors that are associated with PACG and AAC attacks are female sex, age, and race. ${ }^{2,21-23}$
Public health measures to prevent blindness from AAC and PACG will almost certainly involve treating persons with appositional angle-closure who have no evidence of glaucoma or damage to the eye. About 15 percent of Chinese women over the age of 50 have three or more quadrants closed on gonioscopy. ${ }^{9}$ Treating all of these people in order to prevent a disease that affects fewer than 1.5 percent of individuals over the age of 40 may not be warranted. However, because the adverse consequences of LPI in Caucasians are felt to be few, physicians in more developed, usually western countries, routinely perform LPI on most individuals who are PAC suspects. Chinese irides tend to be thick and have few crypts, which can make performing an iridotomy more difficult. LPI typically requires more energy in Chinese eyes, and may have more adverse consequences. Determining which individuals need prophylactic iridotomy is one of the challenges as we move ahead in attempting to prevent PACG in high risk populations.

\section{REFERENCES}

1. Foster PJ, Oen FT, Machin D, et al. The prevalence of glaucoma in Chinese residents of Singapore: a cross-sectional population survey of the Tanjong Pagar district. Arch Ophthalmol 2000;118,1105-11.

2. Foster PJ, Baasanhu J, Alsbirk PH, et al. Glaucoma in Mongolia: a population-based survey in Hövsgöl Province, Northern Mongolia. Arch Ophthalmol 1996;114,1235-41.

3. Dandona L, Dandona R, Mandal P, Srinivas M, John RK, McCarty CA, Rao GN. Angle-closure glaucoma in an urban population in southern India. The Andhra Pradesh eye disease study. Ophthalmology 2000;107(9):1710-6.

4. Quigley HA, Broman AT. The number of persons with glaucoma worldwide in 2010 and 2020. BJO 2006.

5. He M, Foster PJ, Ge J, Huang W, Zheng Y, Friedman DS, Lee PS, Khaw PT. Prevalence and clinical characteristics of glaucoma in adult Chinese: a population-based study in Liwan District, Guangzhou. Invest Ophthalmol Vis Sci 2006;47(7):2782-8.

6. Bonomi L, Marchini G, Marraffa M, Bernardi P, et al. American Academy of Ophthalmology Preferred Practice Patterns: Primary Angle-closure. San Francisco, CA, American Academy of Ophthalmology, 2000.

7. Rotchford AP, Kirwan JF, Muller MA, Johnson GJ, Roux P. Temba glaucoma study: a population-based cross-sectional survey in urban South Africa Ophthalmology 2003;110(2):37682.

8. Mitchell P, Smith W, Attebo K, Healey PR. Prevalence of openangle glaucoma in Australia. The Blue Mountains Eye Study. Ophthalmology 1996;103(10):1661-9.

9. Foster PJ, Johnson GJ. Glaucoma in China: how big is the problem? Br J Ophthalmol 2001;85:1277-82.

10. Weinreb NR, Friedman DS (Eds). Angle-closure and Angleclosure Glaucoma. Kugler Publications: The Hague, The Netherlands, 2006. 
11. Foster PJ, Buhrmann RR, Quigley HA, Johnson GJ. The definition and classification of glaucoma in prevalence surveys. Br J Ophthalmol 2002;86:238-42.

12. Aung T, Ang LP, Chan SP, Chew PT. Acute primary angleclosure: long-term intraocular pressure outcome in Asian eyes. Am J Ophthalmol 2001;131(1):7-12.

13. Lowe RF. Primary angle-closure glaucoma: a review 5 years after bilateral surgery. Br J Ophthalmol 1973;57:457-63.

14. Lowe RF. Acute angle-closure glaucoma the second eye: an analysis of 200 cases. Br J Ophthalmol 1962;46:641-50.

15. Lowe RF, Clark BA. Posterior corneal curvature. Correlations in normal eyes and in eyes involved with primary angle-closure glaucoma. Br J Ophthalmol 1973;57:464-70.

16. Lowe RF, Clark BA. Radius of curvature of the anterior lens surface. Correlations in normal eyes and in eyes involved with primary angle-closure glaucoma. British Journal of Ophthalmology 1973;57:471-4.

17. Lowe RF. Acute angle-closure glaucoma and the crystalline lens. Australian Journal of Ophthalmology 1973;1:89-94.

18. Alsbirk PH. Primary angle-closure glaucoma. Oculometry, epidemiology, and genetics in a high risk population. Acta Ophthalmol 1976;(suppl): 5-31.
19. Devereux JG, Foster PJ, Baasanhu J, Uranchimeg D, Lee PS, Erdenbeleig T, Machin D, Johnson GJ, Alsbirk PH. Anterior chamber depth measurement as a screening tool for primary angle-closure glaucoma in an East Asian population. Arch Ophthalmol 2000;118(2):257-63.

20. Congdon NG, Youlin Q, Quigley H, Hung PT, Wang TH, Ho TC, et al. Biometry and primary angle-closure glaucoma among Chinese, white, and black populations. Ophthalmology 1997;104:1489-95.

21. Congdon NG, Foster PJ, Wamsley S, Gutmark J, Nolan W, Seah SK, Johnson GJ, Broman AT. Biometric gonioscopy and the effects of age, race, and sex on the anterior chamber angle. $\mathrm{Br} \mathrm{J}$ Ophthalmol 2002;86(1):18-22.

22. Seah SK, Foster PJ, Chew PTK, Jap A, Oen F, Fam HB, et al. Incidence of acute primary angle-closure glaucoma in Singapore: an island-wide survey. Arch Ophthalmol 1997;115:1436-40.

23. Wong TY, Foster PJ, Seah SK, Chew PT. Rates of hospital admissions for primary angle-closure glaucoma among Chinese, Malays, and Indians in Singapore. Br J Ophthalmol 2000;84:9902 . 